\title{
A New Approach to the Management of COVID-19. Antagonists of IL-6: Siltuximab
}

\author{
Lucinda Villaescusa (D) · Francisco Zaragozá • Irene Gayo-Abeleira • \\ Cristina Zaragozá
}

Received: November 10, 2021 / Accepted: January 6, 2022 / Published online: January 24, 2022

(c) The Author(s) 2022

\section{ABSTRACT}

Since the beginning of the pandemic, numerous national and international clinical trials have been conducted with a large number of drugs. Many of them are intended for the treatment of other pathologies; however, despite the great effort made, no specific drug is available for the treatment of the symptoms of respiratory disease caused by SARS-CoV-2 infection. The aim of this article is to provide data to justify the use of drugs to tackle the effects produced by IL- 6 as the main inflammatory mediator in patients with COVID-19 with severe respiratory complications, considering all clinical evidence linking the poor prognosis of these patients with increased IL-6 levels in the context of cytokine release syndrome. Furthermore, data are provided to justify the proposal of a rational dosing of siltuximab, a monoclonal antibody specifically targeting IL-6, based on RCP levels, considering the limited results published so far on the use of this drug in COVID-19. A literature search was conducted on the clinical trials of siltuximab published to date as well as on the different IL-6 signalling pathways and the

L. Villaescusa (凹) · F. Zaragozá · I. Gayo-Abeleira ·

C. Zaragozá

Pharmacology Unit, Biomedical Sciences

Department, University of Alcalá, Madrid, 28805

Alcalá de Henares, Spain

e-mail: lucinda.villaescusa@uah.es effects of its overexpression. Knowledge of the mechanisms of action on these pathways may provide important information for the design of drugs useful in the treatment of these patients. This article describes the characteristics, properties, mechanism of action, therapeutic uses and clinical studies conducted with siltuximab so far. The results confirm that administration of siltuximab downregulates IL-6 levels, thereby reducing the inflammatory process in COVID19 patients with severe respiratory disease, suggesting that it can be successfully used to prevent cytokine release syndrome and death from this cause.

Keywords: COVID-19; Cytokine release syndrome; Interleukin-6; Monoclonal antibodies; Siltuximab

\section{Key Summary Points}

Currently, dexamethasone is the only therapeutic treatment approved for COVID-19, and, although other drugs are under evaluation, at present, there is clearly an unmet need in this field

One of the main mediators implicated in the cytokine release syndrome and the key inducer of the inflammatory process in patients with COVID-19 is IL-6, especially in the most severe forms of the disease 
High IL-6 levels have been shown to be predictive of severe respiratory failure and mortality

Data have been published demonstrating the efficacy of targeted therapies to prevent mortality in patients with severe COVID-19, and it is imperative to accelerate their clinical investigation

IL-6 pathway inhibitors have been shown to be effective in patients with severe or critical COVID-19

Blockade of the IL-6 pathway can be accomplished through different mechanisms, inhibiting IL-6 itself (siltuximab), inhibiting signalling through its receptors (tocilizumab) or inhibiting kinases involved in intracellular signalling pathways

The mechanism of action of siltuximab differs significantly from other monoclonal antibodies targeting the IL-6 signalling pathway

Treatment with siltuximab has been shown to downregulate IL-6 levels and consequently reduce the inflammatory process

\section{INTRODUCTION}

It is strange, to say the least, that so many months into the pandemic, humanity still lacks a specific and effective therapy to combat the type of coronavirus that is wreaking havoc on the population.

It is well known that, in the first moments, in the absence of therapeutic proposals, many patients were treated with drugs that failed, as was the case with chloroquine/hydroxychloroquine, although others were more successful in trying to eradicate opportunistic germs (azithromycin).

From the outset, some research groups-such as ours-found that the inflammatory respiratory symptoms induced by the virus had certain parallels to those found in other cases unrelated to COVID. We refer to the symptoms produced by the so-called cytokine storm, which can occur in children treated with CAR-T cells to combat certain leukaemias and in adults treated with the same drug for large B-cell lymphomas [1, 2].

If we focus on the latter, it is known that when CAR-T cells are infused, they recognise tumour cells by the antigen they express, bind to them and induce apoptosis by the mechanisms for which they were designed. However, these mechanisms-mainly pro-apoptotic and lytic_can have adverse effects that need to be specifically addressed. As a cell therapy, the persistence in the body is very long and the possibility of toxicity lasts much longer than with other more commonly used drugs. For the purposes of this article, we consider that its prevention and management are key to therapeutic success. The most important potential adverse effects are cytokine release syndrome (CRS), neurological toxicity, B-cell aplasia and anaphylactic reactions.

Undoubtedly, CRS is the most important adverse effect because of its negative consequences. These are due to an explosive release of cytokines by the high activation of immune cells, which increases the production of IFNgamma, IL-2, IL-6 and IL-10, of which IL- 6 is the most predominant and causes the most damage because of its intense inflammatory properties, resulting in respiratory signs and symptoms such as hypoxia and dyspnoea, as well as high fever, tachycardia, myalgia, severe fatigue, confusion, coagulation disorders, haemoglobin dissociation (with increased ferritin) and renal failure.

CRS is also known as "cytokine storm", an excessive immune reaction that needs to be controlled, given its disproportionate nature, which can lead to death. In principle, it would seem that the way to correct this would be to administer glucocorticoids, but this is not advisable to avoid the loss of $\mathrm{T}$ lymphocytes, which would reduce clinical efficacy. Anti-IL-6 drugs (with other indications) are available in the therapeutic armamentarium, such as tocilizumab [3] and sarilumab [4], which block the 
IL-6 receptor, and siltuximab [5], which blocks IL-6 itself (circulating ligand). They are the best candidates to neutralize the dreaded CRS, although tocilizumab is the only one to have an approved indication to treat CRS. Corticosteroids would obviously be reserved for cases where the patient does not respond quickly to IL-6 pathway blockade.

An interesting parallel. Following the above discussion of CRS in CAR-T cell treatments, it seems appropriate to highlight the parallels between this situation and the severe effects often generated by SARS-CoV-2. If we reproduce the adverse symptoms described above, we find that they mirror the effects occurring in patients with COVID-19, so that the therapeutic consequences are clear, with the advantage in the latter case that corticosteroids can be administered with almost no restrictions.

Deaths from SARS-CoV-2 are still present in unacceptable numbers despite the fact that we-at last-seem to have been using corticosteroid therapy for months now, although it issurprisingly-only authorised in extreme cases.

This is not the case with anti-IL-6 drugs, so we consider it appropriate to make this updated contribution to help clear up doubts about their use, especially focusing on siltuximab, since some observational clinical studies suggest benefits in COVID-19 patients [6].

Additionally, it has the a priori advantageat least theoretically —of directly blocking IL-6, unlike tocilizumab and sarilumab, which block the cytokine receptor [7].

Some issues related to COVID-19. Throughout the time we have been suffering from this pandemic, we have learnt a lot about the disease itself, the symptoms it generates and its interrelation with other pathologies, but not so much about its treatment.

Some monoclonal antibodies that directly tackle SARS-CoV-2 are currently in Phase III, particularly in association [8, 9]. However, it is necessary to emphasise unequivocally that there have been many deaths among critically ill patients admitted to the ICU because of respiratory problems (mainly bilateral pneumonia) caused by CRS, which could have been treated in a specific way, even if it was not included in the therapeutic protocols.
This is a multifaceted problem, but it will not be left unaddressed. Schematically, the disease can have two phases. In the first phase, the virus attaches to and penetrates the respiratory tree via the ACE-2 receptor; this phase is well known and the virus replicates at high speed in an asymptomatic manner with a variable incubation time (2 days to 2 weeks) [10]. The first symptoms appear in the second phase, where the immune system begins to manifest [11]. The process may stop here, without major problems. However, depending on the patient's condition, CRS may develop with an explosive release of inflammatory mediators that complicate his/ her survival [12].

Within this inflammatory phase, there may be other factors such as secondary infections caused by opportunistic agents (bacteria, fungi, other viruses), which contribute to multiplying the excessive and uncontrolled response of the organism. At this point, it is absolutely necessary to modulate the immune response, taking care not to encourage new infections.

This part of the disease is particularly delicate because it is where the patient's life is at stake [13].

Being consistent with our work and knowing specific drugs that can clearly avoid irreversible problems, we here will try to explain the characteristics, properties, mechanism of action, potential therapeutic uses and clinical studies conducted with siltuximab so far as well as a dosage proposal for its successful use.

\section{METHODS}

A literature search of all clinical trials of siltuximab conducted up to the date of submission of this article was conducted for the study. The databases consulted were MEDLINE/PubMed, ClinicalTrials.gov and other official databases. All studies found-of any type-with all sorts of participants and therapeutic interventions were analysed. All included adult patients were critically ill with severe respiratory disease due to COVID-19. The main outcome measures in the clinical trials analysed were C-reactive protein (CRP) levels, time to clinical improvement of 
patients, length of hospitalisation, need for mechanical ventilation and mortality rate.

A search for information related to the different IL-6 signalling pathways was also carried out (Fig. 1), aiming at finding data to help determine the best mechanism of action for the design of drugs useful in the treatment of respiratory disease caused by SARS-CoV-2 infection.

To estimate the optimal dose of siltuximab, an analysis of the pharmacokinetic characteristics was carried out based on the dosing regimen used in each of the pathologies in which clinical studies have been conducted. The pharmacokinetic data analysed were obtained from 14 clinical studies where siltuximab was administered as monotherapy (9) and in combination (5).

This article is based on previously conducted studies and does not contain any new studies with human participants or animals performed by any of the authors.

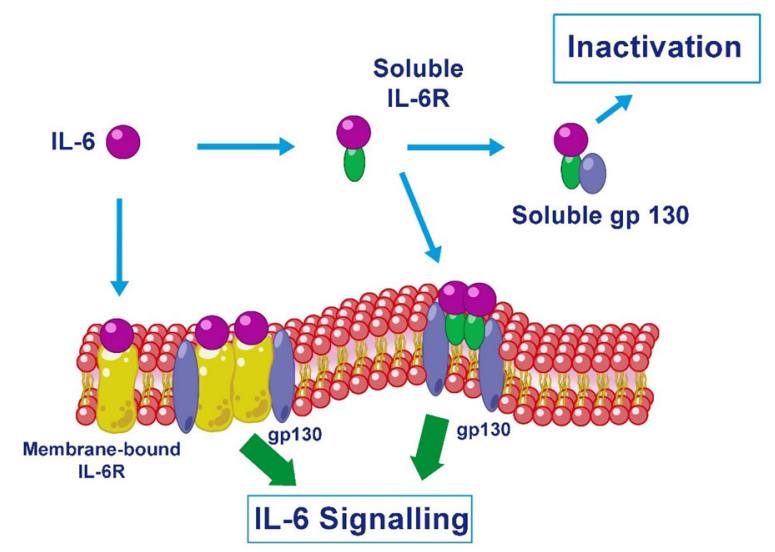

Fig. 1 IL-6R system. IL-6 acts through different signal transduction pathways. In the classical pathway, IL- 6 binds to the transmembrane form of its receptor, IL-6R, which dimerizes. The complex formed binds to the membrane protein gp130 and downstream signaling and gene expression are activated. In the trans pathway, the complex formed by IL-6 and sIL-6R binds to the glycoprotein gp130 and intracellular signal transduction begins

\section{RESULTS}

\section{IL-6. Signalling Pathways}

In 1986, IL-6 was determined to be like a B-cell differentiation factor. The first name of IL- 6 was B-cell stimulating factor (BSF) because the outcomes showed that it acts in activated B cells, turning them into immunoglobulin-producing cells. [14]. It is a small glycoprotein made up of 184 amino acids, forming 4 helices, with 2 $\mathrm{N}$-glycosylation sites and 4 cysteine residues. Its molecular weight ranges from 21 to $30 \mathrm{kD}$ depending on the type and number of posttranslational modifications it undergoes in different tissues [15].

IL- 6 is a multifactorial cytokine that acts as a key player in the mechanism of acute inflammation. It is produced by several cell types, including T cells, B cells, monocytes, fibroblasts, keratinocytes, endothelial cells, mesangial cells, adipocytes and some tumour cells stimulated by Toll-like receptors, which, for their part, boost multiplex cell populations. TNF $\alpha$ and IL-1 $\beta$ are the cornerstones to activate IL- 6 expression [16].

This cytokine acts together with IL-1 in the induction of acute phase protein synthesis. As mentioned above, it also promotes the differentiation of B lymphocytes into plasma cells, inducing the production of immunoglobulins, and enhances IL-2 production and the development of IL-3-dependent haematopoietic precursors.

IL-6, therefore, influences several cell types and exerts multiple biological activities by way of a pair of molecules: IL-6 receptor, IL-6R (otherwise called IL-6R $\alpha$, gp80 or CD126) and the glycoprotein gp130 (IL-6R $\beta$ or CD130) [17]. Both receptor chains are released as soluble functional proteins that circulate in biological fluids.

In humans, a soluble IL-6R (sIL-6R) can be generated, which enables the link to IL-6 (its ligand) by severing the cell membrane proteolytically [18]. The cytoplasmic segment of the mIL-6R is not required for signalling, nor is the transmembrane domain. Therefore, it has been hypothesised that the generation of the sIL-6R 
is a tool to spur cells that solely express gp130, and not IL-6R, as these cells do not respond to IL-6. IL-6 signalling via sIL-6R has been known as "trans-signalling" [19].

In contrast to mIL-6R, there are important sequences for intracellular signalling in the cytoplasmic domain of gp130, while it does not appear to be a kinase domain intrinsically in gp130. However, the cytoplasmic domain of gp130 encloses the regions needed for the union with a non-receptor JAK tyrosine kinase, through which signalling cascades are initiated.

When IL-6 binds to mIL-6R (Fig. 1), homodimerisation of gp130 is induced and a functional high-affinity receptor complex of IL-6, IL6R and gp130 is formed. The soluble form of IL6R (sIL-6R) also binds with IL-6, and the IL-6sIL-6R complex can bind to soluble gp130 (sgp130) forming a ternary complex. It has been suggested that sgp130 acts as a natural inhibitor of sIL-6R receptor trans-signalling responses as a way of preventing widespread stimulation of the IL-6/sIL-6R complex [20].

The presence of both soluble and membranebound receptors allows IL- 6 to expand the scope of its biological activity and interact with a wide variety of cells and tissues.

Homodimerisation of the receptor complex triggers JAK kinases; afterwards, these JAK kinases act in the cytoplasmic domain of gp130 through phosphorylation of tyrosine residues. Since membrane-bound gp130 is displayed ubiquitously in the organism, in theory, the IL6-sIL-6R complex could be able to boost most cells [21].

The sgp130 glycoprotein, by interacting with the IL-6/sIL-6R complex-but not with IL-6 alone, specifically inhibits IL-6 responses mediated by the sIL-6R trans-signalling pathway, while IL-6 responses via the mIL-6R are unaffected. As with membrane-bound gp130, sgp130 only interacts with IL-6 in the presence of sIL-6R.

Considering that IL-6 displays no binding affinity for gp130 when there is a lack of IL-6R, exclusively IL-6R-expressing cells can respond to IL-6. Gp130 shows a widened expression; nevertheless, IL-6R exhibits a limited expression sequence and is mainly limited to leukocyte subsets, megakaryocytes and hepatocytes.
sIl-6R performs two roles: to establish the IL/ sIL-6R complex it protects IL-6 and expands the half-life of this cytokine, though it exerts agonist effects stimulating cells via membranebound gp130. The trans-signalling allows IL-6 to stimulate cells which constitutionally do not possess Il-6 and would not usually react to that interleukin. Likewise, as gp130 shows widened expression, the IL-6/sIL-6R complex could activate cells which do not respond to any other gp130-related cytokine [22].

In short, IL-6 exerts its action through different signal transduction pathways:

- Classic pathway. IL-6 binds to mIL-6R. The complex formed binds to the signal transducer membrane protein glycoprotein gp130, triggering its dimerization and intracellular JAK1/JAK2-STAT3 and MAPK (mitogen-activated protein kinase) signalling and gene expression.

- Trans-signalling pathway. This involves the binding of IL-6 to sIL-6R, forming the IL-6/ sIL-6R complex, which links to gp130 present on the surface of numerous cell types and initiates cell signalling, with results similar to those of the classic pathway, promoting cell proliferation, differentiation, oxidative stress and immune regulation, without the need for the stimulated cell to express IL-6R [23].

IL-6 binds to mIL-6R (classic signalling) or sIL-6R (trans-signalling) or is presented to neighbouring cells via membrane-bound IL-6R (trans-presentation). The latter mode of gp130 activation involves specialised dendritic cells and is necessary for the priming of T-helper 17 (Th17) cells [24].

Therefore, these activities moderate three ways of signalling, although all of them contribute to create a hexameric complex that possesses the transducer: gp130. This signalling mode stimulates the JAK-STAT3 and JAK-MAPK intracellular signalling process. Tyrosine residues moderate different effects. Tyr759 plays a role in the binding of tyrosine phosphatase SHP2, which initiates the MAPK route. However, Il-6 signalling route activates the appearance of two interleukin receptor signalling 
suppressors, such as SOCS1 and SOCS3, which finish the IL-6 signalling pathway effect [25].

Classic signalling is limited to cells expressing mIL-6R (macrophages, neutrophils, T-cells, etc.), although when IL-6 levels rise, as is the case in some COVID-19 patients, IL- 6 binds to the soluble receptor, activating the trans-signalling pathway. This pathway activates a wider range of cells as a result of the omnipresent nature of the gp130 protein, leading to the pleiotropic effects of IL-6.

Control of IL-6 signalling is mediated through the induction of suppressor molecules following activation of IL-6 pathways as well as through the presence of soluble forms of IL-6R and gp130 in blood. The two main IL-6 signalling pathways-classical and trans-signalling-independently induce a wide variety of biological activities. Clinical findings indicate that IL-6 plays several crucial roles in the pathogenesis of autoimmune diseases, haematopoiesis and acute phase reactions. Broadly speaking, the acute phase response participates in the body's recovery from an undesired inflammatory state. This response is swiftly triggered by inflammation linked with infection, injury or other factors and its function is to neutralise pathogens by preventing further invasion and minimising tissue damage. Instead, clinical findings show a surplus production of IL-6 in the pathogenesis of a broad array of illnesses, such as chronic inflammatory diseases or cancer, among others. High IL-6 levels have been found in rheumatoid arthritis (RA), Castleman's disease (CD) and systemic juvenile idiopathic arthritis [21].

\section{Strategies to Block IL-6}

In view of the role of cytokine dysregulation in lung disease in patients with COVID-19 and IL6 being a key factor, notably in severe patients, it is essential to further explore the selective blockade of the IL-6 pathway with drugs capable of reducing downstream signalling pathways, resulting in reduced cell proliferation, differentiation, oxidative stress, exudation and improved clinical findings in patients with unmistakable characteristics of cytokine-induced inflammation.

Usually, it is possible to inhibit the signalling induced by IL- 6 by aiming at the extracellular or intracellular side. The restricted accessibility of intracellular compounds such as kinases makes them a difficult target, while soluble and extracellular proteins, such as IL-6 or sIL-6R, transmembrane domain and mIL-6R, are more specified and simpler targets.

Biological drugs, for example, monoclonal antibodies, can approach the extracellular structures, whereas intracellular signalling can be blocked using inhibitory drugs which have low molecular weight capable of diffusing across the cell membrane [22].

Current studies disclose that selective blockade of distinct IL-6 signalling modes has different clinical outcomes, suggesting different strategies for therapeutic intervention.

Blockade of the IL-6 pathway can be accomplished through different mechanisms, inhibiting IL-6 itself (siltuximab), signalling through its receptors (tocilizumab, sarilumab) or kinases (e.g., JAK/STAT), which are involved in intracellular signalling pathways (ruxolitinib, baricitinib) (Table 1). In this article we focus on the direct blockade of IL- 6 by siltuximab and its therapeutic benefit.

\section{Siltuximab}

Siltuximab (Sylvant ${ }^{\circledR}$ ) is the first and only FDAand EMA-approved monoclonal antibody that specifically binds to IL-6, thereby inactivating IL-6-induced signalling. It is an immunosuppressive drug indicated for the treatment of multicentric Castleman's disease (MCD) in adult patients who are negative for HIV and human herpesvirus-8 (HVH-8). It is administered by iv infusion over $1 \mathrm{~h}$ at a dose of $11 \mathrm{mg} /$ kg every 3 weeks [26].

In Spain, it has been used off label and on an ad hoc basis as therapy of severe respiratory infection with COVID-19. The Spanish Agency for Medicines and Health Products (AEMPS, as per its Spanish acronym) considered patients with severe interstitial pneumonia, rapid worsening requiring ICU admission and invasive or 
Table 1 IL-6 pathway inhibitors

\begin{tabular}{lll}
\hline Drug & Mechanism of action & Indications \\
\hline Siltuximab & IL-6 inhibitor & Multicentric Castleman disease \\
Tocilizumab & IL-6R inhibitor & Giant cell arteritis \\
& & Juvenile rheumatoid arthritis \\
& & Rheumatoid arthritis \\
Sarilumab & IL-6R inhibitor & Cytokine release syndrome \\
Ruxolitinib & JANUS-associated protein kinase (JAK1 and JAK2) inhibitor & Rheumatoid arthritis \\
& & Myelofibrosis \\
Baricitinib & JANUS-associated protein kinase (JAK1 y JAK2, TyK2) inhibitor & Rheumatoid arthritis \\
\hline
\end{tabular}

non-invasive ventilation, extrapulmonary organ failure and severe systemic inflammatory response (IL- $6>50 \mathrm{pg} / \mathrm{ml}$, D-dimer $>1500 \mathrm{ng}$ / $\mathrm{ml}$ or progressively increasing) as candidates for use. In April 2020, it was approved for compassionate use for the treatment of CRS in patients with COVID-19 [27].

In January 2021, the AEMPS determined the medicines considered essential in the management of the health crisis caused by COVID-19, by virtue of the provisions of Article 19.1 of Royal Decree-Law 21/2020, 9 June, on urgent measures for prevention, containment and coordination to deal with the health crisis caused by COVID-19, including siltuximab [28].

\section{How is Siltuximab Obtained?}

To obtain siltuximab, a murine monoclonal anti-IL-6 antibody is first obtained by fusing Sp2/0 mouse myeloma cells with spleen cells from a mouse immunised with recombinant human IL-6 (rHuIL-6). The murine hybridoma cell line secretes a murine monoclonal antibody capable of binding to human IL-6. The variable regions of the heavy and light chains of the antibody are responsible for antigen recognition, so the genes encoding these variable regions were cloned from hybridoma DNA and linked to a human IgG1 constant region gene to express a chimeric monoclonal antibody consisting of the variable regions of the murine antibody and the human constant regions. The cloned genes were transfected into Sp2/0 cells, which ultimately express a chimeric mousehuman monoclonal antibody, siltuximab.

To create a new cell line improved in both cell growth and siltuximab expression capacity, RNA was isolated from a transfected $\mathrm{Sp} 2 / 0$ cell line expressing siltuximab, and RT-RCP was used to clone the complementary DNA (cDNA) of the heavy and light chains of siltuximab. These cDNAs were then cloned into a plasmid expression vector, which was subsequently transfected into Chinese striped hamster ovary (CHO, as per its English acronym) cells to create a stably transfected clonal $\mathrm{CHO}$ cell line capable of expressing siltuximab, registered under the name Sylvant ${ }^{\circledR}$.

Sylvant ${ }^{\circledR}$ is available in vials with 100 or $400 \mathrm{mg}$, depending on the country, for intravenous (iv) infusion. The final product is reconstituted in function of the dose of the vial, with $5.2 \mathrm{ml}$ (for the $100 \mathrm{mg}$ vials) or $20 \mathrm{ml}$ (for $400 \mathrm{mg}$ ones) before use [29].

\section{Description of the Molecule}

Siltuximab is a recombinant chimeric monoclonal antibody (human/murine) of the

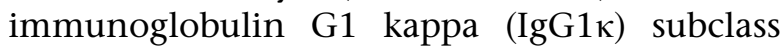
directed against IL-6. It belongs to the 
pharmacotherapeutic group of immunosuppressants, interleukin inhibitors, ATC code: L04AC11.

It has a molecular weight of approximately $147,750 \mathrm{Da}$ and contains 1324 amino acids. There are two heavy chains with exactly 449 amino acids and two light chains with exactly 213 amino acids. Both are combined through non-covalent interactions as well as covalent disulphide connections, and the heavy ones are glycosylated on Asn-299. The N-terminal end of the molecule is made up of glutamic acid at position 1 in the heavy chain and glutamine at position 1 in the light chain. The latter is cyclised to pyroglutamic acid [30].

\section{Mechanism of Action}

Siltuximab binds with high affinity to soluble IL-6, preventing it from binding to both its soluble and membrane receptors (mIL-6R and sIL-6R), which blocks the formation of the hexameric complex with gp130 on the membrane. In the absence of this process, the biochemical signalling of IL-6 is blocked (both classical and trans-signalling) and thus its biological activity (Fig. 2).

\section{Pharmacokinetic Characteristics}

The pharmacokinetic data available have been obtained from nine clinical studies where

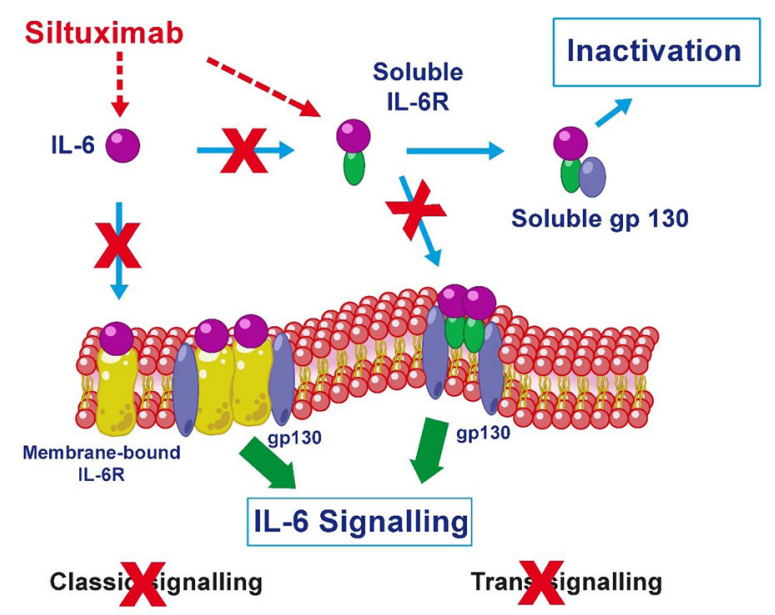

Fig. 2 Mechanism of action of siltuximab siltuximab was administered as monotherapy and five studies where it was administered in combination. After administering the first dose of siltuximab $(0.9-15 \mathrm{mg} / \mathrm{kg})$, AUC and $C_{\max }$ increase dose proportionally, whereas clearance is dose independent. After administering a single dose according to the recommended schedule (11 mg/kg administered once each 21 days), clearance was $3.54 \pm 0.44 \mathrm{ml} / \mathrm{kg} /$ day and halflife was $16.3 \pm 4.2$ days. After repeated dosing, clinical outcomes show that siltuximab's clearance was unchanged over time, and bioaccumulation was moderate. Regarding the plasma half-life found following the initial intake, serum concentrations reach steady-state after infusion number six (3-weekly intervals), with average $\mathrm{Cmax}$ and $\mathrm{Cmin}$ being $332 \pm 139$ and $84 \pm 66 \mu \mathrm{g} / \mathrm{ml}$, respectively [30].

In a $70-\mathrm{kg}$ man, the volume of distribution is 4.5 l. It uses weight-based dosing because the sole variable for siltuximab clearance is the individual weight of each patient. Underpinned by the community pharmacokinetic analysis, siltuximab's clearance in patients is $0.23 \mathrm{l} /$ day. In patients with kidney failure (creatinine clearance $\geq 15 \mathrm{ml} / \mathrm{min}$ ) and light to moderate hepatic disease, siltuximab's clearance remains unchanged. There are insufficient data on the pharmacokinetics of siltuximab in patients with severe kidney or hepatic disease.

A three-part, phase $1 / 2$, multiple-dose pharmacokinetic and pharmacodynamic study of siltuximab in patients with metastatic renal cell carcinoma (RCC) was performed. The onset of the study comprised siltuximab delivery by iv infusion for $2 \mathrm{~h}$ and dose escalation (1 to $12 \mathrm{mg} /$ $\mathrm{kg} / 3$ weeks). The results showed a dose-linked exposure of siltuximab. After the fourth administration of siltuximab, the steady-state was not achieved; the clearance and volume of distribution was found to be dose independent. Its plasma half-life was approximately 17 days [31].

A phase 1 pharmacokinetic study included 67 patients with non-Hodgkin's lymphoma (NHL), multiple myeloma (MM) and CD. Increasing doses of siltuximab (2-h iv infusion) of $3 \mathrm{mg} / \mathrm{kg}$ each 14 days, $6 \mathrm{mg} / \mathrm{kg}$ each 14 days, $12 \mathrm{mg} / \mathrm{kg}$ each 21 days, $6 \mathrm{mg} / \mathrm{kg} /$ week and $12 \mathrm{mg} / \mathrm{kg}$ each 14 days were used in different 
cohorts, increasing the intake intensity to 1.5 , 3,4 and $6 \mathrm{mg} / \mathrm{kg} /$ week. The treatment period was 43 days. Serum siltuximab concentrations decreased biexponentially, with a final half-life after the first administration of 17.73-20.64 days. Clearance was $4.03-4.59 \mathrm{ml} / \mathrm{day} / \mathrm{kg}$. Following the initial dose and after multiple doses, proportional dose relative increases in $C_{\max }$ and AUC were found. Accumulation after multiple doses was consistent with the half-life of the final phase after the early dose, so it follows that there is no time-dependent variability in the pharmacokinetic. Comparing the pharmacokinetic profiles of different patients with NHL, MM or CD, the outcomes do not show significant differences [32].

In the phase 1 study of siltuximab in MCD, the researchers obtained similar pharmacokinetic parameters to the reported one in the RCC trial [32].

A pharmacokinetic analysis using a twocompartment model adequately described the time course of siltuximab serum concentration after multiple iv administrations in 378 patients with MCD, CD, RCC, NHL, MM, prostate cancer, ovarian cancer and latent $\mathrm{MM}$ who received siltuximab as monotherapy at doses ranging from 0.9 to $15 \mathrm{mg} / \mathrm{kg}$. The values for clearance, central compartment volume of distribution, intercompartmental clearance and peripheral compartment volume of distribution in a $70-\mathrm{kg}$ man were $0.223 \mathrm{l} /$ day, $4.54 \mathrm{l}, 0.448 \mathrm{l} /$ day and 3.391 , respectively. Age, race, sex, baseline creatinine clearance, baseline alanine aminotransferase (ALT), baseline albumin and concomitant corticosteroid use had no clinically relevant effect on clearance. As mentioned above, the only clinical variable that has a relevant statistically significant impact on the whole siltuximab pharmacokinetic parameters is the body weight. This is why the dosing strategy was based on the individual mass of each patient [29].

Siltuximab is catabolised into small peptides and amino acids. However, it can obstruct with CYP450 activity. Treatment with siltuximab can lead to an intensified metabolism of CYP450 substrates, especially CYP3A4. This may be because CYP450 enzymes are inhibited by cytokines such as IL-6 in case of infection and inflammation. Consequently, drug levels should be checked during treatment and the dose adjusted if necessary.

\section{SILTUXIMAB AND COVID-19}

\section{Clinical Trials in COVID-19}

\section{SISCO Study (Siltuximab in Serious COVID- 19) (NCT 04322188)}

This is a retrospective, single-centre, observational, cohort study evaluating iv siltuximab treatment in patients with COVID-19 who suffer severe respiratory complications, like the patients who need ventilation, whether it is invasive or not. In this study, the data gathering was carried out on patients registered in the ReCOVID10-2020 study and those to whom siltuximab was given. All these patients received standard treatment and were in-patients from 23 February to 13 March 2020 at the Papa Giovanni XXIII Hospital, Bergamo, Italy.

The study included 220 patients. Thirty were treated with siltuximab together with best supportive care and the control cohort group was treated with best supportive care alone. Patients treated with siltuximab received a dose of $11 \mathrm{mg} / \mathrm{kg}$ infused over $1 \mathrm{~h}$, with a second dose after $72 \mathrm{~h}$ at medical discretion. CRP levels decreased from baseline to day 5 after siltuximab treatment in all patients with sufficient values recorded $(100 \%, 16 / 16)$. This level of reduction was maintained in these patients $(100 \%, 16 / 16) 7$ days after treatment with siltuximab. Reduced CRP levels are considered a very valid marker to indicate the efficacy of IL- 6 inhibition.

The 30-day mortality rate was significantly lower in siltuximab-treated patients than in the control cohort. Median follow-up was 33.3 days for siltuximab-treated patients and 22.8 days for the control cohort; 33\% $(n=7)$ of patients experienced clinical improvement with a reduced need for oxygen support and 43\% $(n=9)$ of patients saw their condition stabilise. In contrast, disease worsening was found in three $(14 \%)$ patients, while one $(5 \%)$ patient died and one $(5 \%)$ patient experienced a cerebrovascular event, which was not considered 
treatment-related. The results suggest that patients with rapidly progressing COVID-19 respiratory failure requiring ventilatory support may benefit from treatment with siltuximab to reduce mortality and hyperinflammation associated with severe disease [33].

The authors of this study also examined the relationship among siltuximab treatment, serum levels of different cytokines and chemokines, and mortality and/or pulmonary function in in-patients who suffer from COVID19 and acute respiratory distress syndrome in a prospective, observational cohort study. The drug was administered to 30 patients with severe COVID-19 requiring ventilatory support under a compassionate use programme. The cytokines under analysis were pentraxin 3 (PTX3), IL-8, IL-10, IL-12, TNF, CXCL10/IP-10, CXCL9/MIG, CCL2/MCP-1 and sCD163. The researchers laid down the response to treatment as a decrease in the requirement of ventilatory support and resolution of the symptomatology of COVID-19. The results indicate that the change in cytokine profile after siltuximab treatment can be considered prognostic of outcome. Clinical findings reveal that siltuximab has a local effect of IL-6 inhibition in cutting down pulmonary inflammation by modulation of PTX3 [34, 35]. Furthermore, siltuximab also modulates IL-8 levels suggesting a suppressing of organic inflammation, which can prevent IL8-mediated neutrophil recruitment and activation $[36,37]$. Siltuximab showed beneficial effects in decreasing local and systemic inflammation, which were mirrored in enhanced survival and pulmonary function in patients with severe COVID-19 with moderate CRS [38-40].

\section{EudraCT 2020-001413-20 (SILCOR-COVID19) (NCT04329650)}

This is a phase 2, randomised, open-label study to compare the efficacy and safety of siltuximab in contrast to methylprednisolone in 200 inpatients who suffered pneumonia caused by COVID 19. Siltuximab is administered as a single dose of $11 \mathrm{mg} / \mathrm{kg}$ by intravenous infusion. The comparator, methylprednisolone, is administered at a dose of $250 \mathrm{mg} / 24 \mathrm{~h}$ for 3 days followed by $30 \mathrm{mg} / 24 \mathrm{~h}$ for 3 days by intravenous infusion. If patients are being treated with lopinavir/ritonavir, both doses of methylprednisolone are halved. The primary study variable is the fraction of patients who required to be admitted to the ICU at any time during the study interval. The study is currently recruiting. No results have been published so far [41].

\section{COV-AID Study (NCT04330638)}

The purpose of this prospective, multicentre, interventional, randomised, prospective study is to analysis the safety and efficacy of single or simultaneous IL- 6 and IL-1 blockade compared to standard therapy on blood oxygenation and CRS in patients who suffer COVID-19 and acute hypoxic pulmonary disease and CRS. This is a phase 3 study involving 342 patients from 16 Belgian hospitals.

After a fortnight with the treatment, clinical condition is evaluated to measure the efficacy of tocilizumab, tocilizumab and anakinra, siltuximab, siltuximab and anakinra and anakinra in recovery pulmonary homeostasis, using iv siltuximab or tocilizumab combined or not with subcutaneous doses of anakinra every day until the 28th day or hospital discharge.

The primary endpoint is time to clinical improvement defined as the time from randomisation to a two-point improvement on a six-category ordinal scale measured daily until day 28 or hospital discharge or death. The study is still recruiting. No results have been published so far [42].

\section{Clinical Outcome of the Combination of Corticosteroids and Anti-IL-6 Drugs Versus Both Drugs in Monotherapy in Patients with CRS due to SARS-CoV-2 Infection (NCT04486521)}

This is a prospective observational cohort and disease registry study to assess the safety and efficacy of the combination of corticosteroids and anti-IL-6 drugs (tocilizumab and siltuximab) versus both groups of drugs in monotherapy in critically ill patients with COVID-19 pneumonia (data from 11,000 patients are expected to be obtained). This study will provide more information on whether antiIL-6 drug or corticosteroid monotherapy 
provides the same efficacy and clinical outcome with a reasonable side effect profile compared to anti-IL-6 drug together with corticosteroid. Anti-IL-6 drugs could serve as corticosteroidsparing agents in COVID-19 patients with CRS.

This study is an example of a rapidly implemented international pandemic registry aimed at providing near real-time analysis and information on treatment and critical care outcomes for patients with coronavirus disease [43].

SILVAR (SILtuximab in Viral ARDS): a Study Comparing the Efficacy and Safety of Standard of Care with or Without Siltuximab in Selected Hospitalized Patients with Viral Acute Respiratory Distress Syndrome (SILVAR) (NCT04616586)

In July 2020, the FDA approved a phase 3 clinical trial protocol for siltuximab. The SILVAR study is a multicentre, randomised, doubleblind, placebo-controlled study to evaluate the safety and efficacy of iv siltuximab in addition to standard care in in-patients with COVID-19 associated ARDS. The multi-centre trial will enrol about 400 patients with high serum IL-6 levels. The principal aim is to asses 28-day allcause mortality adding siltuximab to conventional treatment and contrasting with placebo and conventional treatment. Subsidiary endpoints for a normal male include time for clinical situation improvement, time in the ICU, days without organic disruption, days without ventilation, respiratory function and stay in hospital.

Randomization is carried out based on three main groups (age, respiratory virus infection and MIV status). All patients receive ARDS standard of care following official international guidelines. Patients may continue receiving their corticosteroid or antiviral therapy (with the exclusion of special cases) at the same or diminished posology if started at least 4 days (in the first case) or at least 2 days (in the second case) before randomization. Siltuximab $11 \mathrm{mg} /$ $\mathrm{kg}$ iv will be given to patients included into arm A of the study for $1 \mathrm{~h}$, whereas those included in arm B will also receive iv NS for $1 \mathrm{~h}$. Occasionally, it was possible to readminister their assigned study treatment if the study protocol conditions were met [44].
The first patient, from Sparrow Hospital, Lansing, Michigan, was included in December 2020. Nevertheless, this study was terminated by the sponsor in April 2021 because the results of the REMAP-CAP and RECOVERY studies seem to underpin the survival advantage of tocilizumab in patients with COVID-19 associated ARDS in critical conditions whether treated with corticosteroids or untreated.

It should be noted that the retrospective studies reviewed were heterogeneous, and the results were not conclusive. Other drugs studied showed similar effects to tocilizumab, but the available data to confirm such effects were insufficient, so these estimates should be carefully analysed.

A prospective meta-analysis of several randomised clinical trials conducted by the WHO Rapid Evidence Appraisal for COVID-19 Therapies (REACT) Working Group evaluated the efficacy of tocilizumab, sarilumab and siltuximab in COVID-19 patients. The main objective of the assay was to study the association between the administration of these drugs and 28-day mortality versus standard treatment or placebo. Data from 27 RCTs, involving a total of 10,930 patients from 28 countries, were analysed. Nineteen trials included tocilizumab as an intervention, nine trials with sarilumab and only one trial with siltuximab. Administration of anti-IL- 6 monoclonal antibodies was associated with lower mortality after 28 days. The simultaneous administration of IL-6 pathway inhibitors and corticosteroids provides better results than each drug in monotherapy. The best results of associations were those involving tocilizumab. The authors point out that this study has certain limitations. One is that some of the mentioned trials were not finished at the time of publication of the meta-analysis and have not been published in peer-reviewed journals. Another important limitation is the paucity of siltuximab results versus corticosteroids, so the results cannot be conclusive [45].

Several independent clinical trials have been initiated worldwide to date to explore the safety and efficacy of siltuximab for the treatment of patients with severe COVID-19, including the SISCO trial discussed above; however, validation of the results obtained through 
randomised, well-controlled clinical studies is required.

The clinical trials described are summarized in Table 2.

\section{Clinical Safety and Adverse Effects}

According to the data on the product label, adverse reactions (ADRs) identified include pruritus, upper respiratory tract infection, maculopapular rash, localised oedema, weight gain, stomach ache, common cold, thrombocytopenia, kidney failure, hypertriglyceridaemia, high blood pressure, neutropenia and anaphylaxis.

ADRs were detected based on events recorded in the pivotal CNTO328MCD2001 study, which occurred in $\geq 10 \%$ of subjects at the posology used $(11 \mathrm{mg} / \mathrm{kg}$ every 3 weeks) compared to the placebo group.

Hypertension, neutropenia, thrombocytopenia, nasopharyngitis and anaphylactic reaction were identified as ADRs based on the plausibility of an association based on the mechanism of action of siltuximab. Rash and diarrhoea were not identified as ADRs. Rash was considered less specific than maculopapular rash, already identified as an ADR. The higher incidence of diarrhoea found in the monotherapy studies ( $14 \%$ in placebo versus $25 \%$ in the target dose) may be due to symptoms related to the underlying disease in subjects with solid tumours in the CNTO328STM2001 study.

It has been established that live attenuated vaccines should not be administered at the same time or within 4 weeks before starting treatment with siltuximab, since clinical safety has not been established and because IL-6 inhibition can hinder the ordinary immune response to new antigens.

Throughout clinical trials the researchers noted serious infections, such as pneumonia and sepsis. Siltuximab can camouflage the symptomatology of acute inflammation, with reduction of fever and acute phase reactants such as CRP, among others, and the patient should be monitored for serious infections.
Concerning lipid parameters, patients to whom siltuximab was given show increases in the levels of triglycerides and cholesterol.

In terms of immunogenicity production, analysis of available serum samples from $>600$ subjects in all monotherapy and combination clinical studies showed a low risk of immunogenicity (generation of antibodies against siltuximab). Antibodies to the drug were detected in a sample from a patient treated with siltuximab in study CNTO328MCD2001; however, it was determined that the anti-siltuximab antibodies were not neutralising. There was no apparent effect of immune response on safety and efficacy. No other subjects in any other clinical studies with siltuximab have reported detectable antibodies to siltuximab at any time to date.

In the phase 1 pharmacokinetic study involving 67 patients with NHL, MM and CD, no dose-related toxicity was found. Most adverse effects were slight, other than grade 3-4 neutropenia (21\%) and hypertension (9\%). 66\% of patients had infection, but most of them were low grade. In the midst of these infections the most common are those related to the upper airway (39\%), urinary system (16\%), sinusitis $(12 \%)$ and cellulitis (9\%); of these, one case of upper respiratory tract infection and four cases of cellulitis resulted in grade $\geq 3$ [32].

In the phase 2 study in CD patients, a minimum of one dose was postponed in 21 patients $(40 \%)$ receiving siltuximab because of neutropenia. In the siltuximab arm, the most frequent adverse events over this phase differed from the outcomes of the Phase 1 research, including pruritus in 22 individuals (42\%), upper airway infection in 19 individuals (36\%), overtiredness in 18 individuals (34\%), maculopapular rash in 18 individuals (34\%) and peripheral oedema in 17 individuals (32\%). Neutropenia and thrombocytopenia occurred in seven individuals (13\%) and eight individuals $(15 \%)$ of the siltuximab-treated patients, respectively, and no lipid abnormalities were disclosed. The $6 \%$ of the individuals (3) who received siltuximab experienced serious siltuximab-related adverse reactions, such as lower airway infection, anaphylactic response, or 


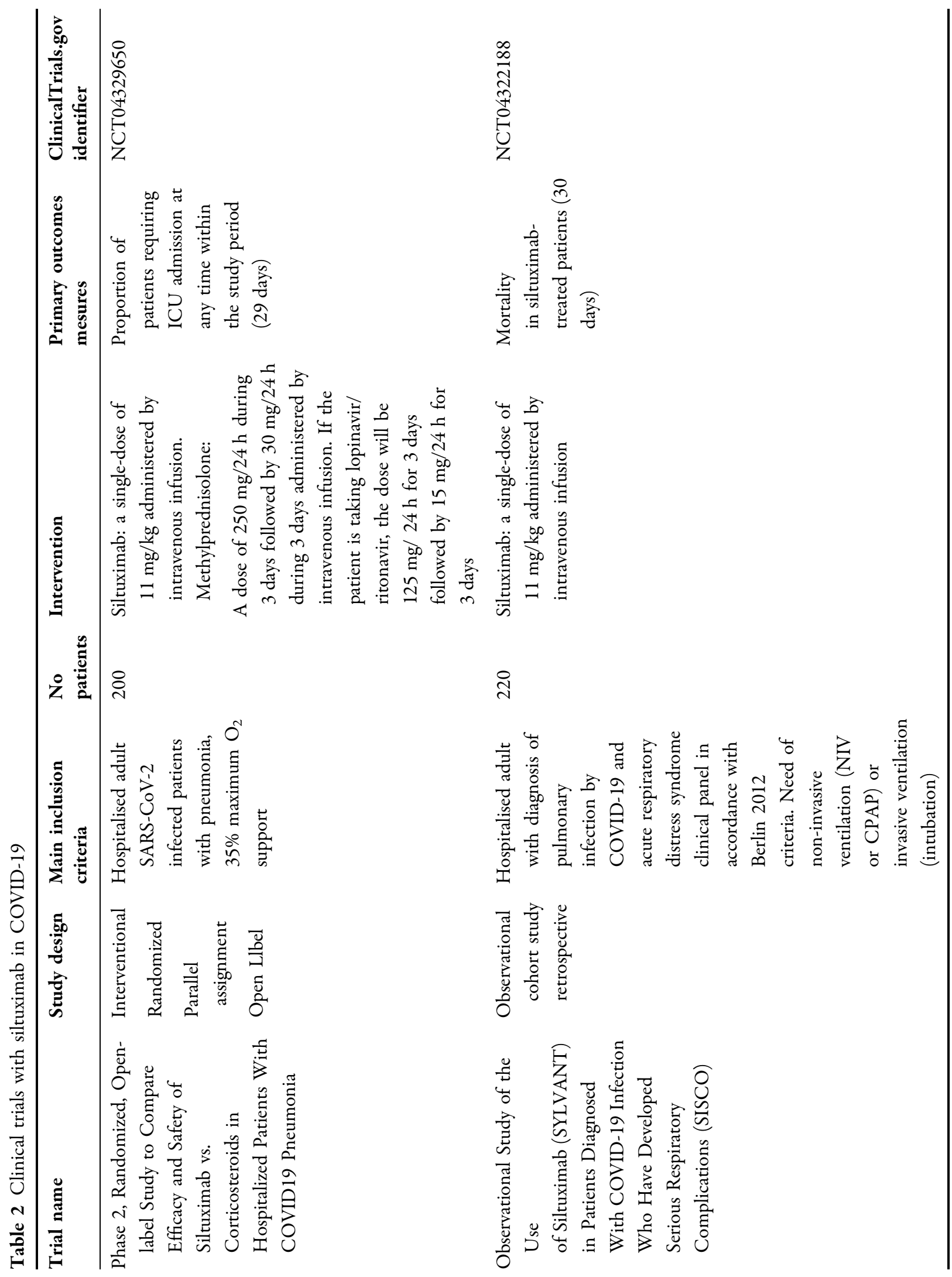




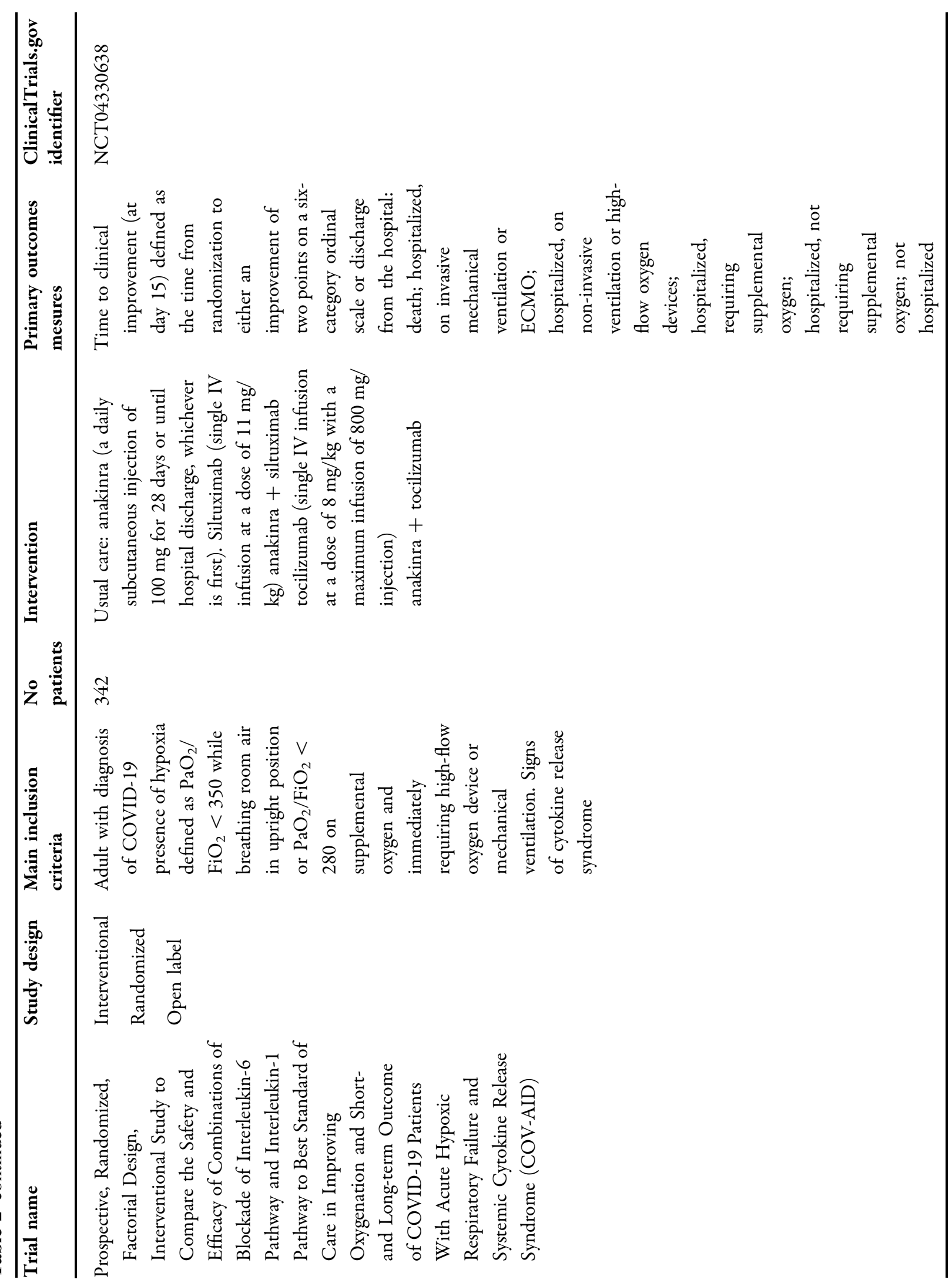




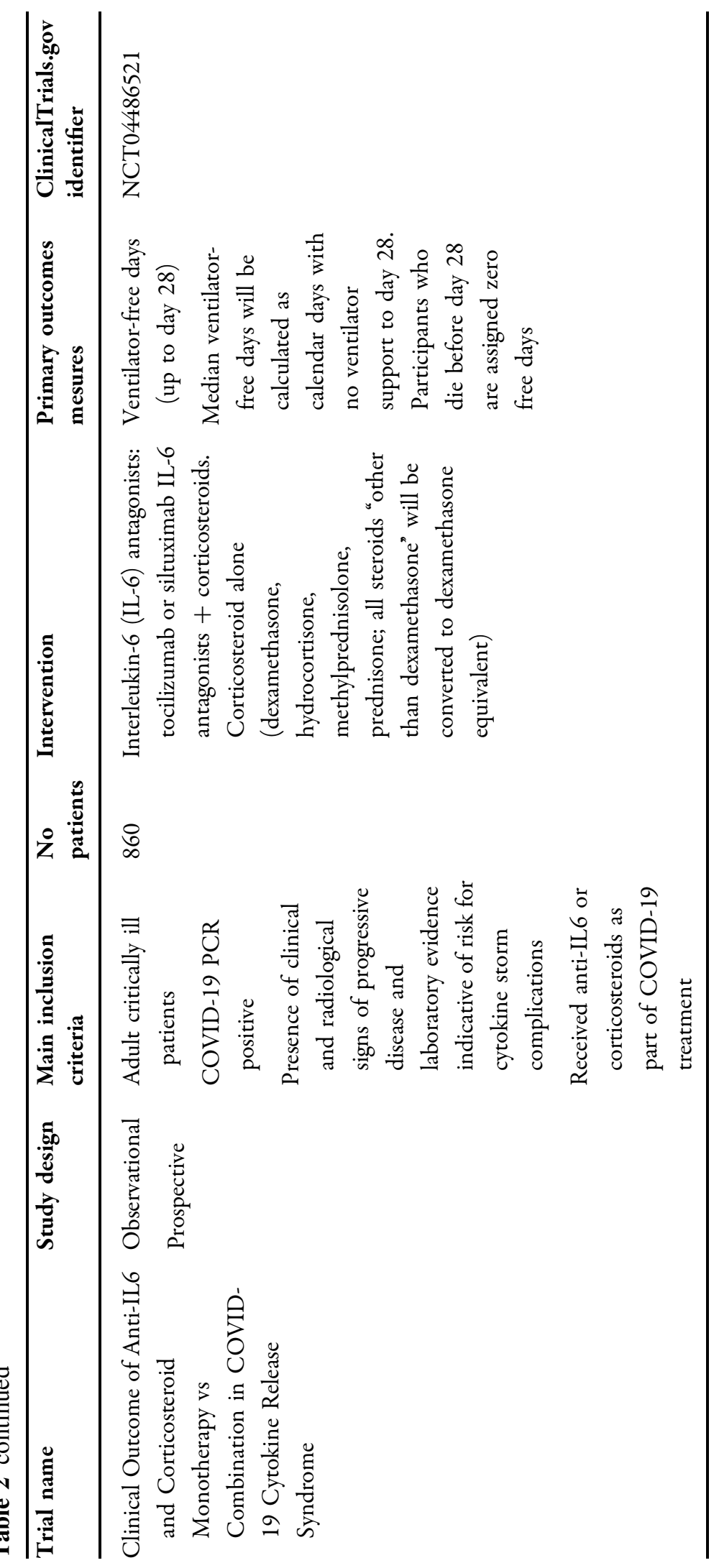




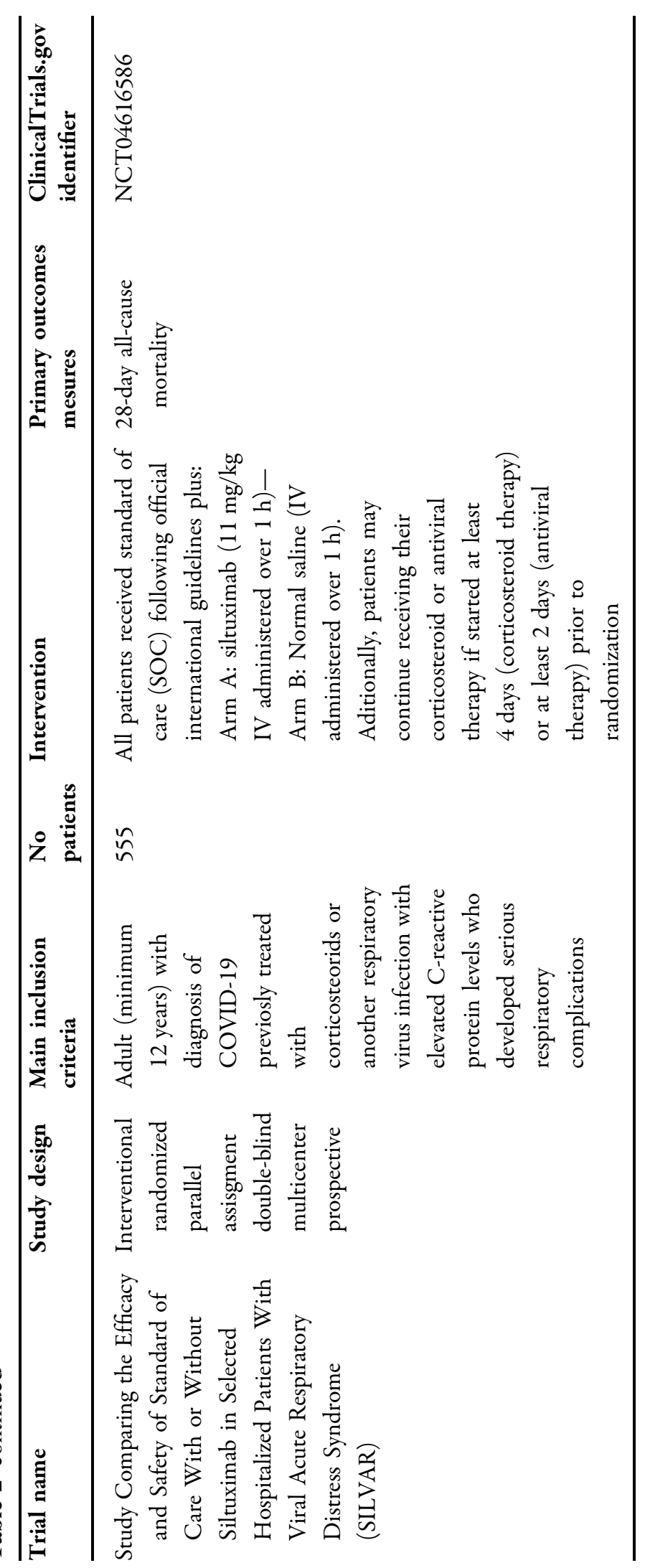


sepsis. No mortality related to the study drug was identified [46].

A provisional interim assay of the phase 2 extension study in patients with MCD showed long-term safety. Siltuximab was generally well tolerated showing few serious adverse effects and no evidence of treatment interruption or cumulative toxicity. Side effects in the longerterm subgroups ( $\geq 2-4$ years of treatment) resembled the short-term ( $0-2$ years) ones or were diminished. Notably, in the present survey, no patients suffered perfusion-associated reactions to this monoclonal antibody [47].

In the observational SISCO study in patients with COVID-19, the 30-day mortality rate was significantly lower in patients treated with siltuximab. Worsening of the disease was found in three $(14 \%)$ patients, while one $(5 \%)$ patient died and one (5\%) patient experienced a cerebrovascular event, which was not considered treatment related [33].

\section{CONSIDERATIONS RELATED TO DOSE ESTIMATION OF SILTUXIMAB IN THE TREATMENT OF RESPIRATORY INFECTION IN PATIENTS WITH COVID-19}

In general, most drugs are dosed by calculating the maximum tolerated dose (MTD) based on dose-limiting toxicity. This is the classic dosefinding design and is based on the traditional oncology belief that the more, the better and that a higher dose will produce greater clinical activity. However, the era of targeted therapy has incorporated other dose-finding strategies: the determination of the optimal biological dose (OBD). In the case of monoclonal antibodies, dose setting requires a greater understanding of and attention to pharmacodynamic effects because they are usually well tolerated. In general terms, the recommended OBD would not be based on toxicity. For example, increasing doses would be administered to reach a predefined pharmacological parameter, until a target is saturated with the drug or until a biological pathway mediated by the target is optimally altered.

Moreover, it should be remembered that exposure to therapeutic monoclonal antibodies has a high individual variability. This means that the pharmacokinetic profile of a particular antibody, and therefore its efficacy, will vary from one individual to another depending on different characteristics such as the affinity of the drug for its target, levels of the target in the body, distribution of the drug in tissues and concentration of the drug in the body.

There is no consensus on how to establish the optimal therapeutic dose for each drug, as it largely depends on the therapeutic target. Soluble ligands, such as cytokines, are an important target for therapeutic monoclonal antibodies. The therapeutic efficacy of these antibodies is theoretically related to the magnitude and duration of the reduction in free ligand levels. However, in the case of soluble ligands with rapid clearance, it is difficult to assess the decrease in the amount of free ligand [48]. In the specific case of siltuximab, accurate quantification of IL-6 after treatment is currently not feasible, as IL-6-siltuximab complexes interfere with available immunoassays for IL-6 measurement.

Comparing healthy individuals with inflammatory states, an increase of IL-6 production and sIL-6R concentrations over the second condition was found, while sgp130 levels were widely preserved. Furthermore, the affinity of IL-6 for its receptor (IL-6R) is largely lower than the affinity of IL-6 for sIL-6R. Consequently, a large amount of sIL-6R and sgp130 in the blood is a regulatory mechanism to reduce IL-6 levels. Given that the concentration of sgp130 surpasses sIL-6R levels, the concentration of sIL-6R is the limiting step in the regulation of IL- 6 blood levels [49-54].

The recommended dose and dosing schedule $(11 \mathrm{mg} / \mathrm{kg} / 3$ weeks or $15 \mathrm{mg} / \mathrm{kg} / 4$ weeks) in MCD was established primarily based on the tumour response achieved and the correlation between IL-6 levels and CRP suppression, reflecting the neutralisation of IL- 6 biological activity. Mayer et al. used a PK/PD model to select the appropriate dose for clinical development of siltuximab in the treatment of MCD 
based on the CRP levels achieved [26]. This optimal dose-finding strategy using PK/PD simulation is mainly possible for large molecules directed at a specific target, as dose selection is not limited by MTD [55].

In the case of $\mathrm{CD}, \mathrm{B}$-cell $\mathrm{NHL}$ and $\mathrm{MM}$, simulations showed that $11 \mathrm{mg} / \mathrm{kg}$ every 3 weeks or $15 \mathrm{mg} / \mathrm{kg}$ every 4 weeks reduces serum CRP below $1 \mathrm{mg} / \mathrm{l}$ after the second dose for the entire treatment period. However, diseases with potentially higher IL-6-associated CRP production may require higher or more frequent doses of siltuximab.

In a study involving $\mathrm{MM}$ patients treated with murine anti-IL-6 monoclonal antibody and anti-IL6 BE-8, an increase in daily IL-6 production in vivo from several $\mu \mathrm{g} /$ day to $\mathrm{mg} /$ day was shown. In individuals with decreases in IL-6 production, total inhibition of CRP production and objective response to antitumour therapy were found. In the same study, using serum CRP levels as a marker of IL-6 bioactivity in vivo, it was shown that anti-IL-6 monoclonal antibody completely blocked IL-6's effect in individuals producing $<18 \mu \mathrm{g} /$ day, showing an objective anti-tumour response [49]. According to the authors of this study, in some patients, the dose of anti-IL- 6 monoclonal antibody administered could be 100 times lower to neutralise huge IL-6 production in vivo and to control CRP production and tumour growth.

In MM patients, a siltuximab concentration of $5 \mu \mathrm{g} / \mathrm{ml}$ was proposed to achieve a 300-fold molar excess of siltuximab related to IL-6, which is considered necessary to block IL-6 activity and tumour growth [56].

In a phase I study in individuals who had metastatic RCC, administration of $6 \mathrm{mg} / \mathrm{kg}$ siltuximab every 14 days effectively discontinued serum CRP in patients with a baseline CRP level $\leq 30 \mathrm{mg} / \mathrm{l}$. These figures match the pharmacokinetic parameters of siltuximab. It was shown that such doses reduced CRP below the LLOQ [31].

Another important issue that must be considered is that therapeutic monoclonal antibodies can trigger an immune response. In many cases this results in the development of anti-drug antibodies, leading to increased clearance of the drug and thus a decrease in its plasma levels. In the specific case of siltuximab, the presence of anti-drug antibodies has not been detected.

\section{DISCUSSION}

COVID-19 is an acute respiratory disease caused by a highly pathogenic coronavirus, severe acute respiratory syndrome virus type 2 (SARSCoV-2). SARS-CoV-2 infection triggers the innate immune system leading to an excess of response that may be related to increased lung damage and worse clinical outcome. As noted throughout the article, there may be two different phases of the disease, occurring consecutively in the most severe cases, although there is as yet no clear explanation as to why the second phase occurs mostly in older individuals. The first phase is triggered by the virus and the second by the host response. The treatment should be different in each of these phases. Supportive measures are the care standard, intended for controlling temperature, dehydration, constitutional and other clinical expressions. Given the unprecedented circumstances of the COVID-19 pandemic, and in the absence of drugs and treatment guidelines, intensive research has been conducted in recent months and the use of certain drugs outside their initial indications has been encouraged. Efforts have been made to repurpose other clinically available drugs that have been tested in vitro or have been proposed as potentially useful for their mechanism of action. Likewise, new and experimental drugs with likelihood antiviral characteristics are being examined. However, therapies that modulate the hyperinflammatory host reaction are being envisaged as well. In some cases, it is assumed that the administration of antiviral drugs has benefits over the earliest disease stage when the illness is mediated by active viral replication. Immunomodulatory agents are assessed to be used over the subsequent proinflammatory course, which generally manifests as clinical worsening during the second week since symptom beginning.

The virus affects not only the lungs but also other tissues. Numerous studies have demonstrated the existence of increased levels of IL-6 
and other pro-inflammatory cytokines in subjects who suffer severe COVID-19 [57]. In addition to IL-6, the presence of IL-2, IL-7, IL-8, G-CSF, IL-17, TNF $\alpha$ and other markers indicating systemic inflammatory response have been detected. Significant production of cytokines and chemokines results in the recruitment of lymphocytes and leukocytes to the location of the infection. Nevertheless, a huge discharge of cytokines may take place in the framework of a positive feedback loop associated with the amplification of the immune response [11]. Hyperactivation of the immune system can lead to lymphocyte depletion associated with increased tissue damage, which is clinically observable in severe patients presenting with lymphopenia and hyperferritinaemia. This CRS would be associated with ARDS, which is found in the severe prognosis of COVID-19 coronavirus disease and has been described as the leading cause of mortality [13]. CRS therefore occurs when there is massive activation of leukocytes (neutrophils, macrophages and mast cells), which release a significant quantity of pro-inflammatory cytokines and other inflammatory mediators in an uncontrolled manner, which at the same time can boost alveolarcapillary gas exchange, hence reducing oxygenation in lung tissue. This syndrome was initially described as an adverse effect of treatment with monoclonal antibodies, such as blinatumomab, and is also common in patients treated with CAR-T cells (chimeric antigen receptor T cells) [2]. In the latter case, treatment with IL-6 pathway inhibitors is recommended [58].

Large amounts of pro-inflammatory cytokines result in massive infiltration of immune cells of the lungs in individuals suffering from COVID-19, giving rise to alveolar injury, lower lung function and quick evolution to death. IL6 is one of the major cytokines concerned with the pathogenesis of CRS and the crucial driver of the inflammatory process in subjects who suffer COVID-19, especially in the most severe forms of the illness, and has therefore been established as a preferential target in COVID-19.

Moreover, IL- 6 has been found to be the main inducer of CRP synthesis in hepatocytes. High CRP levels have been correlated with serum IL-6 in many types of tumours and also in inflammatory diseases, CRP may therefore be a pharmacodynamic marker of IL-6 bioactivity [33].

The two main IL-6 signalling pathwaysclassical and trans-signalling-independently induce a wide variety of biological activities. Clinical findings suggest that IL-6 plays a number of critical roles in the pathogenesis of autoimmune diseases, haematopoiesis and acute phase reactions. Moreover, as mentioned above, IL-6 signalling occurs via a soluble and a membrane-bound receptor and these two pathways differ greatly in their biological consequences. While classical IL-6 signalling through the mIL-6R is mainly regenerative and protective, trans-IL- 6 signalling through the sIL$6 \mathrm{R}$ is rather pro-inflammatory. The complex biology of IL- 6 has implications for the therapeutic targeting of this cytokine. It is presumed that specific inhibition of the trans-signalling pathway may be greater than global blockade of IL- 6 activity with the help of antibodies directed against IL-6 or IL-6R.

Generally speaking, the acute phase response is involved in the body's recovery from an unwanted inflammatory state. This response is rapidly induced by inflammation associated with infection, injury or other factors and its function is to neutralise pathogens by preventing further invasion and minimising tissue damage. In contrast, overproduction of IL- 6 has been identified in the pathogenesis of a wide range of diseases, including chronic inflammatory diseases and cancer. High IL-6 levels have been found in rheumatoid arthritis (RA), CD and systemic juvenile idiopathic arthritis [21].

The IL- 6 pathway can be blocked through different strategies: TK inhibitors and anti-IL-6 and anti-IL-6R monoclonal antibodies. Drugs that inhibit the IL-6 pathway have been proved effective against COVID-19. The efficacy of these drugs is determined by the inhibition of CRP levels and dosing is based on the CRP levels achieved.

Evidence is available on the use of monoclonal antibodies targeting the IL- 6 receptor (soluble and membrane) (tocilizumab and sarilumab) and the soluble IL-6 ligand (siltuximab). Siltuximab binds with high affinity to 
soluble IL-6, blocking its biological activity and preventing its binding to both membrane and soluble receptors.

There are also data on the effect of anti-IL-6 monoclonal antibodies on CRS caused by CAR$\mathrm{T}$ cell administration, which might suggest a similar effect in COVID-19, although IL-6 levels in both situations have not been studied comparatively.

During the clinical development of siltuximab in CD, it was also studied in other pathologies, such as MM, NHL and several solid tumours, where it did not show significant benefit. The selection of the starting dose of siltuximab for the clinical trials in COVID-19 was based on previous studies in patients with different tumour types. The dose varies depending on the disease because of the different levels of IL-6 and CRP in each disease. In the case of $\mathrm{CD}$, the established dose is $11 \mathrm{mg} / \mathrm{kg} /$ 3 weeks. For MM, given the absence of toxicity, the selected dose is $11 \mathrm{mg} / \mathrm{kg} / 3$ weeks. In these patients, daily IL-6 production is around $60 \mu \mathrm{g} /$ day. A useful PK/PD model for dose selection has been established in RCC. The recommended doses are $6 \mathrm{mg} / \mathrm{kg}$ every 2 weeks and $9 \mathrm{mg} / \mathrm{kg}$ every 3 weeks. These doses keep CRP levels below the detectable limit [32].

In MM, NHL and CD siltuximab has linear pharmacokinetics. $\mathrm{C}_{\max }$ and AUC increase in proportion to the dose [32]. Simulations (PK/PD model) showed that $6 \mathrm{mg} / \mathrm{kg}$ siltuximab every 2 weeks or $9 \mathrm{mg} / \mathrm{kg}$ every 3 weeks reduces serum CRP below $4 \mathrm{mg} / \mathrm{l}$. At the lowest doses tested (1 and $3 \mathrm{mg} / \mathrm{kg}$ ), no reduction of CRP below $1 \mathrm{mg} / \mathrm{l}$ is obtained. Siltuximab has a slow clearance, with a t1/2 of approximately 3 weeks [31]. CRP levels have been related to drug clearance, such that the higher the CRP levels are, the greater the clearance. Therefore, the higher the serum IL-6 levels are, the greater the clearance of the drug. In healthy individuals, clearance is slower.

Apparently, no differences in the pharmacokinetic characteristics of siltuximab have been found in patients with different pathologies (NHL, MM, CD).

As for safety, this is one of the most worrying issues, especially regarding the risk of infections, mainly with the concomitant use of antiIL-6 monoclonal antibodies and corticosteroids.

\section{CONCLUSIONS}

After analysis of the results, we believe it is important to highlight the importance of the potential benefits of siltuximab in the inflammatory phase of the disease, should it occur, given that excessive cytokine release (especially IL-6) is the main cause of SARS-CoV-2-induced death.

Siltuximab is a drug that has proved to be safe and effective in humans for another previously approved indication, CD.

However, based on what has been stated in this article, we find it appropriate to use a dose of $11 \mathrm{mg} / \mathrm{kg}$, but because the half-life of siltuximab is $16.3 \pm 4.2$ days and this viral infection is an acute process, we consider that a single dose could be sufficient for the downregulation of IL-6 levels and the consequent reduction of the inflammatory process, without prejudice against the possibility of administering a second dose depending on the patient's situation, especially in relation to the improvement of respiratory function, in addition to other symptoms such as fever and the levels of inflammatory markers, etc.

In short, all data suggest that siltuximab is an excellent candidate for improving the inflammatory phase of COVID-19; therefore, a priori it has a good chance of improving the incidence of mortality in this serious disease, although validated and properly designed clinical trials are needed to confirm the clinical use of siltuximab compared to other IL-6 pathway blocking drugs.

\section{ACKNOWLEDGEMENTS}

Funding. No funding or sponsorship was received for this study or publication of this article. The journal's Rapid Service and Open Access Fees were funded by the authors.

Authorship. All named authors meet the International Committee of Medical Journal Editors (ICMJE) criteria for authorship for this article, take responsibility for the integrity of 
the work as a whole, and have given their approval for this version to be published.

Author Contributions. Lucinda Villaescusa: Conceptualization, Methodology, Formal analysis, Supervision, Eriting original draft, Writing-review and Editing; Francisco Zaragozá: Conceptualization, Methodology, Formal analysis, Supervision, Writing original draft, Writing-review and editing; Irene Gayo-Abeleira: Methodology, Formal analysis; Cristina Zaragozá: Methodology, Formal analysis, Writing-review and editing, Supervision.

Disclosures. Lucinda Villaescusa, Francisco Zaragozá, Irene Gayo-Abeleira and Cristina Zaragozá declare that they have no conflicts of interest.

Compliance with Ethics Guidelines. This article is based on previously conducted studies and does not contain any new studies with human participants or animals performed by any of the authors.

Data Availability. All data generated or analyzed during this study are included in this published article/as supplementary information files.

Open Access. This article is licensed under a Creative Commons Attribution-NonCommercial 4.0 International License, which permits any non-commercial use, sharing, adaptation, distribution and reproduction in any medium or format, as long as you give appropriate credit to the original author(s) and the source, provide a link to the Creative Commons licence, and indicate if changes were made. The images or other third party material in this article are included in the article's Creative Commons licence, unless indicated otherwise in a credit line to the material. If material is not included in the article's Creative Commons licence and your intended use is not permitted by statutory regulation or exceeds the permitted use, you will need to obtain permission directly from the copyright holder. To view a copy of this licence, visit http://creativecommons.org/licenses/bync/4.0/.

\section{REFERENCES}

1. Shimabukuro-Vornhagen A, Gödel P, Subklewe M, et al. Cytokine release syndrome. J Immunother Cancer. 2018;6:56.

2. Riegler LL, Jones GP, Lee DW. Current approaches in the grading and management of cytokine release syndrome after chimeric antigen receptor T-cell therapy. Ther Clin Risk Manag. 2019;15:323-35.

3. Sheppard M, Laskou F, Stapleton PP, Hadavi S, Dasgupta B. Tocilizumab (Actemra). Hum Vaccin Immunother. 2017;13:1972-88.

4. Lamb YN, Deeks ED. Sarilumab: a review in moderate to severe rheumatoid arthritis. Drugs. 2018;78:929-40.

5. Abramson JS. Diagnosis and management of Castleman disease. J Natl Compr Cancer Netw. 2019;17:1417-9.

6. Meira F, Albiach L, Carbonell C, et al. Experience with the use of siltuximab in patients with SARSCoV-2 infection. Rev Esp Quimioter. 2021;34: $337-41$.

7. Avci AB, Feist E, Burmester GR. Targeting IL-6 or IL6 receptor in rheumatoid arthritis: what's the difference? BioDrugs. 2018;32:531-46.

8. Gottlieb RL, Nirula A, Chen P, et al. Effect of bamlanivimab as monotherapy or in combination with etesevimab on viral load in patients with mild to moderate COVID-19. JAMA. 2021;325:632-44.

9. Ledford H. COVID antibody treatments show promise for preventing severe disease. Nature. 2021;591:513-4.

10. $\mathrm{Xu} \mathrm{H}$, Zhong L, Deng J, et al. High expression of ACE2 receptor of 2019-nCoV on the epithelial cells of oral mucosa. Int J Oral Sci. 2020;12:1-5.

11. Li G, Fan Y, Lai Y, et al. Coronavirus infections and immune responses. J Med Virol. 2020;92:424-32.

12. Zhou Y, Fu B, Zheng X, et al. Pathogenic T-cells and inflammatory monocytes incite inflammatory storms in severe COVID-19 patients. Natl Sci Rev. 2020;7:998-1002.

13. Ruan Q, Yang K, Wang W, Jiang L, Song J. Clinical predictors of mortality due to COVID-19 based on an analysis of data of 150 patients from Wuhan, China. Intensive Care Med. 2020;1:1-3. 
14. Hirano T, Yasukawa K, Harada H, et al. Complementary DNA for a novel human interleukin (BSF2) that induces $B$ lymphocytes to produce immunoglobulin. Nature. 1986;324:73-6.

15. Simpson RJ, Hammacher A, Smith DK, Matthews JM, Ward LD. Interleukin-6: structure-function relationships. Protein Sci. 1997;6:929-55.

16. Hunter CA, Jones SA. IL-6 as a keystone cytokine in health and disease. Nat Immunol. 2015;16:448-57.

17. Hibi M, Murakami M, Saito M, Hirano T, Taga T, Kishimoto T. Molecular cloning and expression of an IL-6 signal transducer, gp130. Cell. 1990;63: 1149-57.

18. Mülberg J, Schooltink H, Stoyan T, et al. The soluble interleukin-6 receptor is generated by shedding. Eur J Immunol. 1993;23:473-80.

19. Rose-John S, Heinrich PC. Soluble receptors for cytokines and growth factors: generation and biological function. Biochem J. 1994;300(Pt 2):281-90.

20. Jostock T, Müllberg J, Ozbek S, et al. Soluble gp130 is the natural inhibitor of soluble interleukin-6 receptor transsignaling responses. Eur J Biochem. 2001;268:160-7.

21. Mihara M, Hashizume M, Yoshida H, Suzuki M, Shiina M. IL-6/IL-6 receptor system and its role in physiological and pathological conditions. Clin Sci (Lond). 2012;122:143-59.

22. Jones SA, Scheller J, Rose-John S. Therapeutic strategies for the clinical blockade of IL-6/gp130 signaling. J Clin Invest. 2011;121:3375-83.

23. Bower M, Stebbing J. Exploiting interleukin 6 in multicentric Castleman's disease. Lancet Oncol. 2014;15:910-2.

24. Heink S, Yogev N, Garbers C, et al. Trans-presentation of interleukin- 6 by dendritic cells is required for priming pathogenic TH17 cells. Nat Immunol. 2017;18:74-85.

25. Kang S, Tanaka T, Narazaki M, Kishimoto T. Targeting interleukin-6 signaling in clinic. Immunity. 2019;50:1007-23.

26. Mayer CL, Xie L, Bandekar R, et al. Dose selection of siltuximab for multicentric Castleman's disease. Cancer Chemother Pharmacol. 2015;75:1037-45.

27. Agencia Española de Medicamentos y Productos Sanitarios. Tratamientos disponibles para el manejo de la infección respiratoria por SARS-CoV-2 [Internet]. 2020. Available from: https://www.aemps.gob. es/laAEMPS/docs/medicamentos-disponibles-SARSCoV-2-16-4-2020.pdf. Accessed 11 Oct 2021
28. BOE.es-BOE-A-2021-150 Resolución de 15 de diciembre de 2020, de la Agencia Española de Medicamentos y Productos Sanitarios, por la que se modifica la Resolución de 19 de junio, de la Agencia Española de Medicamentos y Productos Sanitarios, por la que se establecen los medicamentos considerados esenciales en la gestión de la crisis sanitaria ocasionada por el COVID-19, en virtud de lo dispuesto en el artículo 19.1 del Real Decreto-ley $21 / 2020$, de 9 de junio, de medidas urgentes de prevención, contención y coordinación para hacer frente a la crisis sanitaria ocasionada por el COVID19. [Internet]. 2021. Available from: https://www. boe.es/diario_boe/txt.php?id=BOE-A-2021-150. Accessed 22 Jul 2021

29. Research J. Protocol CNTO328MCD2002; Phase 2 Amendment INT-4. 2014;71.

30. Anonymous. Sylvant [Internet]. European Medicines Agency. 2018. Available from: https://www. ema.europa.eu/en/medicines/human/EPAR/ sylvant. Accessed 22 Jul 2021

31. Puchalski T, Prabhakar U, Jiao Q, Berns B, Davis HM. Pharmacokinetic and pharmacodynamic modeling of an anti-interleukin- 6 chimeric monoclonal antibody (siltuximab) in patients with metastatic renal cell carcinoma. Clin Cancer Res. 2010;16:1652-61.

32. Kurzrock R, Voorhees PM, Casper C, et al. A phase I, open-label study of siltuximab, an anti-IL-6 monoclonal antibody, in patients with B-cell non-Hodgkin lymphoma, multiple myeloma, or Castleman disease. Clin Cancer Res. 2013;19:3659-70.

33. Gritti G, Raimondi F, Ripamonti D et al. IL-6 signalling pathway inactivation with siltuximab in patients with COVID-19 respiratory failure: an observational cohort study. medRxiv. Cold Spring Harbor Laboratory Press; 2020;2020.04.01. 20048561

34. Brunetta E, Folci M, Bottazzi B, et al. Macrophage expression and prognostic significance of the long pentraxin PTX3 in COVID-19. Nat Immunol. 2021;22:19-24.

35. Schirinzi A, Pesce F, Laterza R, et al. Pentraxin 3: potential prognostic role in SARS-CoV-2 patients admitted to the emergency department. J Infect. 2021;82:84-123.

36. Del Valle DM, Kim-Schulze S, Huang H-H, et al. An inflammatory cytokine signature predicts COVID19 severity and survival. Nat Med. 2020;26: 1636-43.

37. Meizlish ML, Pine AB, Bishai JD, et al. A neutrophil activation signature predicts critical illness and 
mortality in COVID-19. Blood Adv. 2021;5: 1164-77.

38. Gritti G, Raimondi F, Bottazzi B, et al. Siltuximab downregulates interleukin-8 and pentraxin 3 to improve ventilatory status and survival in severe COVID-19. Leukemia. 2021;1:1-5.

39. Zumla A, Hui DS, Azhar EI, Memish ZA, Maeurer M. Reducing mortality from 2019-nCoV: host-directed therapies should be an option. Lancet. 2020;395: e35-6.

40. The ARDS Definition Task Force. Acute respiratory distress syndrome: the Berlin definition. JAMA. 2012;307:2526-33.

41. Efficacy and Safety of Siltuximab vs. corticosteroids in hospitalized patients with COVID-19 Pneumonia-full text view-ClinicalTrials.gov [Internet]. Available from: https://clinicaltrials.gov/ct2/show/ NCT04329650. Accessed 22 Jul 2021

42. Maes B, Bosteels C, De Leeuw E, et al. Treatment of severely ill COVID-19 patients with anti-interleukin drugs (COV-AID): a structured summary of a study protocol for a randomised controlled trial. Trials. 2020;21:468.

43. Walkey AJ, Kumar VK, Harhay MO, et al. The viral infection and respiratory illness universal study (VIRUS): an international registry of coronavirus 2019-related critical illness. Crit Care Explor. 2020;2:e113.

44. EusaPharma (UK) Limited. A study comparing the efficacy and safety of standard of care with or without siltuximab in selected hospitalized patients with viral acute respiratory distress syndrome (SILVAR) [Internet]. clinicaltrials.gov; 2021 Report No.: NCT04616586. Available from: https:// clinicaltrials.gov/ct2/show/NCT04616586

45. The WHO Rapid Evidence Appraisal for COVID-19 Therapies (REACT) Working Group. Association between administration of il-6 antagonists and mortality among patients hospitalized for COVID19: a meta-analysis. JAMA. 2021;326:499-518.

46. van Rhee F, Wong RS, Munshi N, et al. Siltuximab for multicentric Castleman's disease: a randomised, double-blind, placebo-controlled trial. Lancet Oncol. 2014;15:966-74.

47. van Rhee F, Casper C, Voorhees PM, et al. A phase 2, open-label, multicenter study of the long-term safety of siltuximab (an anti-interleukin-6 monoclonal antibody) in patients with multicentric Castleman disease. Oncotarget. 2015;6:30408-19.

48. Chan AC, Carter PJ. Therapeutic antibodies for autoimmunity and inflammation. Nat Rev Immunol. 2010;10:301-16.

49. Lu ZY, Brailly H, Wijdenes J, Bataille R, Rossi JF, Klein B. Measurement of whole body interleukin-6 (IL-6) production: prediction of the efficacy of antiIL-6 treatments. Blood. 1995;86:3123-31.

50. Schaper F, Rose-John S. Interleukin-6: biology, signaling and strategies of blockade. Cytokine Growth Factor Rev. 2015;26:475-87.

51. Rose-John S. IL-6 trans-signaling via the soluble IL-6 receptor: importance for the pro-inflammatory activities of IL-6. Int J Biol Sci. 2012;8:1237-47.

52. Nowell MA, Richards PJ, Horiuchi S, et al. Soluble IL-6 receptor governs IL-6 activity in experimental arthritis: blockade of arthritis severity by soluble glycoprotein 130. J Immunol. 2003;171:3202-9.

53. Waage A, Brandtzaeg $\mathrm{P}$, Halstensen A, Kierulf $\mathrm{P}$, Espevik T. The complex pattern of cytokines in serum from patients with meningococcal septic shock. Association between interleukin 6, interleukin 1, and fatal outcome. J Exp Med. 1989;169: 333-8.

54. Scheller J, Rose-John S. The interleukin 6 pathway and atherosclerosis. Lancet. 2012;380:338.

55. Marshall JL. Maximum-tolerated dose, optimum biologic dose, or optimum clinical value: dosing determination of cancer therapies. J Clin Oncol. 2012;30:2815-6.

56. van Zaanen HC, Lokhorst HM, Aarden LA, et al. Chimaeric anti-interleukin 6 monoclonal antibodies in the treatment of advanced multiple myeloma: a phase I dose-escalating study. Br J Haematol. 1998;102:783-90.

57. Conti P, Ronconi G, Caraffa A, et al. Induction of pro-inflammatory cytokines (IL-1 and IL-6) and lung inflammation by Coronavirus-19 (COVI-19 or SARS-CoV-2): anti-inflammatory strategies. J Biol Regul Homeost Agents. 2020;34:327-31.

58. Liu B, Li M, Zhou Z, Guan X, Xiang Y. Can we use interleukin-6 (IL-6) blockade for coronavirus disease 2019 (COVID-19)-induced cytokine release syndrome (CRS)? J Autoimmun. 2020;111:102452. 